\title{
A Study to Assess the Effectiveness of Structured Teaching Programme Regarding Knowledge on Management of Febrile Convulsion among Mothers of under Five Children in Rajarajeswari Medical College and Hospital, Bangalore
}

\author{
Jyothy George ${ }^{1}$, Jophin Joseph ${ }^{2}$ \\ ${ }^{1}$ Department of Pediatric Nursing, RajaRajeswari College of Nursing Bangalore-74, India \\ ${ }^{2}$ Department of Nursing and Midwifery, College of public health and medical Sciences, Jimma University, PO.Box:1104, Jimma, Ethiopia,
} India

\begin{abstract}
Background: Children under five years of age are more prone to develop infection, as their immune system is immature. Fever is a common manifestation present in most of the infection. In some children severe fever can result convulsion. Febrile convulsions generate as much anxiety among relatives and parents. Nursing care should be directed toward educating the child and family . Nurse should educate the parents about condition, how to treat fever at home and first aid if child has convulsion and educate about when to call ambulance. The objective of the study was to assess the pretest knowledge, posttest knowledge and its comparison on management of febrile convulsion among mothers of under five children and to determine the association between posttest knowledge score on management of febrile convulsion with their selected demographic variables of mothers of under five children. Method: A pre experimental one group pretest and posttest design was used to conduct the study among 60 mothers of under five children who were selected by convenience sampling technique for the study. The data was collected through structured interview schedule to assess the knowledge of mothers of under five children regarding management of febrile convulsion. The study was conducted in RajaRajeswari General Hospital, Bangalore. The data collected and analyzed based on descriptive and inferential statistics. Result: The result of the study showed that the mean knowledge score in pretest was 11.5 and SD was 3.59 and in posttest mean was 24.41 and SD 3.2. So it is evident that mean posttest knowledge of mothers of under five children regarding management of febrile convulsion was significantly greater than their mean pretest knowledge score. ${ }^{\prime}{ }^{\prime}=37.6$ significant at $p<0.01$ level, df 59. Thechisquare test revealed that there was a significant association of knowledge with selected demographic variables such as type of family, educational status, income and previous history of hospitalization. Interpretation and conclusion: The present study proved that the structured teaching program was significantly effective in improving the knowledge of mothers of under five children regarding management of febrile convulsion. Hence the study concluded that improve the knowledge on management of febrile convulsion helps to provide care, to safeguard the children during febrile convulsion and to prevent further complication.
\end{abstract}

Keywords: Structured teaching program, Effectiveness, Knowledge, Mothers, Under five children, Febrile convulsion.

\section{Introduction}

Children under five years of age are very small and their all systems are in developing stage. Because of their play activities, poor feedings and immaturity of immune system causes frequent attack of infections like respiratory tract infection, otitis media, diarrhoea, gastroenteritis etc. Fever is a common manifestation present in most of the infection. In some children severe fever can result convulsion. A febrile convulsion is a seizure occurring in a child, precipitated by a fever arising from infection outside the nervous system in a child who is otherwise neurologically normal. Febrile convulsions have long been recognized, but only in recent years more fully understood. Hippocrates, writing in the 4th century BC, described such a convulsion, clearly differentiating it from rigors and breath holding attacks. He noted that both generalized and partial seizures can occur, and realized that there was a strong association with age, high fever and a precipitating infection.

Febrile convulsions are fits occurring in children associated with fever without other underlying causes such as central nervous system infection or electrolyte imbalance. The febrile convulsion may be divided in to 1) Simple, begin and 2) Atypical, complex. Simple convulsion is generalized tonic-clonic convulsion lasting less than 15 minutes that do not recur within 24 hours or within the same febrile illness. The complex febrile convulsion is lasting more than 15 minutes; recurrence is within 24 hours or within the same febrile illness [1]. Approximately one in every 25 children will have at least 1 febrile convulsion and more than one third of these children will have additional febrile convulsion before they outgrow the tendency to have them. Children rarely develop their first febrile seizure before the age of 6 month or after 3 years of age [2].The studies demonstrated that $80 \%$ of febrile convulsion is simple. Where as child with a simple febrile seizure has a $98 \%$ probability of not developing epilepsy. When children with febrile convulsion are compared with their siblings at the age of 7 years there is no difference in the mean full scale IQ score [3].

Febrile Convulsion is one of the commonest disorders of the childhood and it causes lot of worries to the parents and care givers. It accounts almost $50 \%$ of the convulsive disorders, 


\section{International Journal of Science and Research (IJSR) \\ ISSN (Online): 2319-7064}

Index Copernicus Value (2013): 6.14 | Impact Factor (2014): 5.611

and according to American Academy of Pediatrics (AAP); febrile convulsion affects $3 \%$ of children age ranging from 6 months to 5 years [4]. The prevalence of febrile convulsion in Asia is 3-9/1000 population and in India is 5.59/1000 population. The prevalence rate of febrile convulsion in south India is $4.14 / 1000$ population and there is a slight predominance of males (prevalence rate of .1/1000 for boys, $0.02 / 1000$ for girls) $[1,5]$. It was identified by investigator during her clinical experience at RajaRajeswari Medical College and Hospital Bangalore that many mothers of under five children having anxiety and less awareness regarding how to manage their baby during febrile convulsion.

A prospective population-based study conducted in Department of Public Health, University of Turku, Turku, Finland concluded that incidence rate of febrile convulsion was higher in girls than boys [6]. Another prospective population based study conducted in Department of Pediatrics, Ayub Medical College, Pakistan shows that majority of febrile convulsions occurred in first two years of life and it was common in children with positive family history of convulsion [7].A cohort study conducted in department of pediatrics Arhus University Hospital, Denmark concluded that the risk of further febrile convulsions varied with the age at first convulsion and the presence of a history of convulsive disorders in relatives [8]. Furthermore a Retrospective study conducted in selected hospital Karnataka to determine the incidence of febrile convulsion, the study concluded that Febrile convulsions is most common problem in pediatric practice and incidence rate of febrile convulsion in male is higher compare to females [9].

Many mothers of under five children having anxiety and less awareness hence they require educational programs. A crosssectional study conducted in healthcare centers in Arak city on knowledge of mothers on management of febrile convulsion the study concluded that there was lack of knowledge regarding febrile convulsion among mothers so required elaborate educational programme [10]. Another prospective questionnaire-based study was carried out at Department of Pediatrics, University of Baghdad concluded that improved health education is required to allay mothers fear and anxiety and promote a more appropriate fever management at home[11]. In addition to that a prospective questionnaire based study conducted in Seth G. S. Medical College \& K. E. M. Hospital, Mumbai concluded that parental fear of fever and febrile convulsion is a major problem with serious negative consequences so they need appropriate education [12].

\section{Objectives of the Study}

1) To assess the pretest knowledge on management of febrile convulsion among mothers of under five children.

2) To assess the posttest knowledge on management of febrile convulsion among mothers of under five children after structured teaching programme.

3) To compare the pretest score and post test score of knowledge on management of febrile convulsion among mothers of under five children.

4) To determine the association between posttest knowledge score on management of febrile convulsion with their selected demographic variables of mothers of under five children.

\section{Materials and Method}

The research design selected for this study was pre experimental one grouppretestposttest design and the study was conducted in the pediatric ward at Raja Rajeswari Medical College and Hospital, Bangalore. The population consists of all the mothers of under five children admitted in pediatric ward at Rajarajeswari Medical College and Hospital during the period of data collection. The sample size was 60 mothers of under five children who met the inclusion criteria were included in the study. The convenience sampling technique was adopted to select the sample for the present study.

\section{Criteria for selecting sample:}

i) Mothers of under five children.

ii) Mothers who are willing to participate in the study.

iii) Mothers who knows Kannada.

iv) Mothers who come in pediatric ward at RajaRajeswari Medical College and Hospital, Bangalore.

\section{Description of the Tool}

Structured interview schedule was used as the research tool. The tool consists of three sections:

- Section I: It consisted of 10 items describing the sociodemographic variables such as age, type of family, place of residence, religion, educational status, occupational status, income, and number of children, source of information and previous history of hospitalization.

- Section II: The questionnaire was constructed with a total number of 30 items. Each item having four options, for correct answer the score is one and wrong answer the score is zero. The total score is 30 .

- Section III: structured teaching module on febrile convulsion. it was organized in the following areas

- Meaning, list out the classification of febrile convulsion

- describe the pathophysiology of febrile convulsion

- list out the clinical manifestation of febrile convulsion

- how to diagnose febrile convulsion

- explain the management of febrile convulsion

The level of knowledge is classified as

1. Inadequate Knowledge - $<50 \%$

2. Moderate Knowledge- $51-75 \%$

3. Adequate Knowledge $->76 \%$

The investigator first introduced her to the participants and obtained their verbal consent. Participants were given pretest using structured interview schedule. After the pretest the investigator administered structured teaching programme regarding management of febrile convulsion for 30 minutes using laptop. At the end of structured teaching programme 10 minutes was allotted for discussion. The post test was conducted after 5 days using same structured interview schedule. The same procedure was followed for all the samples.

\section{Volume 4 Issue 11, November 2015}




\section{International Journal of Science and Research (IJSR) \\ ISSN (Online): 2319-7064 \\ Index Copernicus Value (2013): 6.14 | Impact Factor (2014): 5.611}

\section{Result}

\section{Demographic Data}

It is showed that out of 60 sample majority26 (43.33\%) were in the age group of $20-25$ years, $42(70 \%)$ of samples were belongs to nuclear family. Majority $42(70 \%)$ of samples belongs to rural and their religion revels $36(60 \%)$ of the subjects were Hindus. Among 60 samples 20 (33.33\%) had high school education moreover the large proportion $46(76.67 \%)$ of samples were homemakers and $26(43.33 \%)$ had their income between 5001-10000(INR). 31(51.67\%) having two children and $18(30 \%)$ participants acquired information from health care professionals. Highest percentage $41(68.33 \%)$ of them had no history of hospitalization before.

\section{Pretest Knowledge}

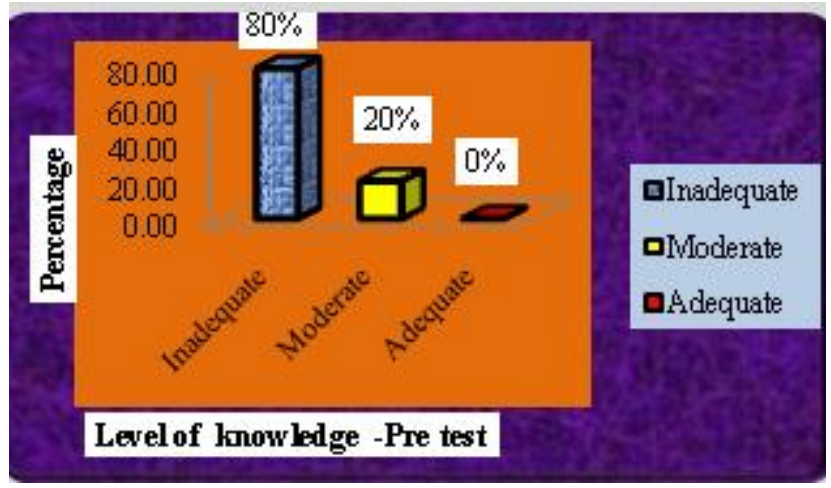

Figure 1: Showed that in pretest $48(80 \%)$ having inadequate, $12(20 \%)$ moderate and no one having adequate knowledge regarding management of febrile convulsion
Table 1: Mean, SD and Mean\% of the pretest knowledge on management of febrile convulsion among mothers of under five children, $\mathrm{n}=60$

\begin{tabular}{|c|c|c|c|}
\hline Level of knowledge & Mean & $S D$ & Mean\% \\
\hline Overall & 11.55 & 3.59 & 38.50 \\
\hline
\end{tabular}

The table 1. Showed that over all pretest mean score are 11.55, SD 3.59 and mean percentage is 38.5.

\section{Post-Test Knowledge}

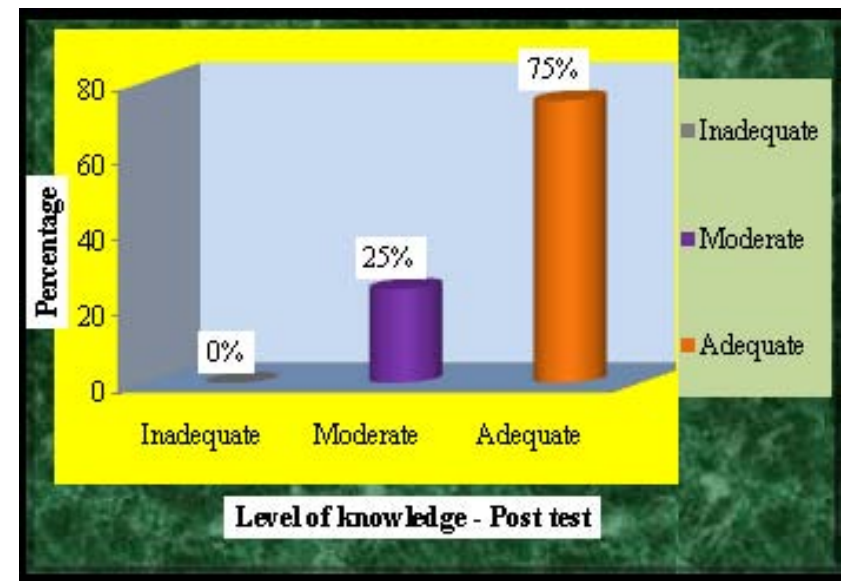

Figure 2 showed that in posttest $45(75 \%)$ having adequate, $15(25 \%)$ moderate, and no one having inadequate knowledge regarding management of febrile convulsion.

Table 2: Mean, SD and Mean\% of the posttest knowledge on management of febrile convulsion among mothers of under five children, $\mathrm{n}=60$

\begin{tabular}{|l|c|c|c|}
\hline Level of Knowledge & Mean & SD & Mean $\%$ \\
\hline Overall & 24.41 & 3.2 & 81.37 \\
\hline
\end{tabular}

The table 2 shows that the overall post- test mean is 24.41 , SD 3.2 and mean percentage 81.37.

\section{Comparison of pretest post-test knowledge}

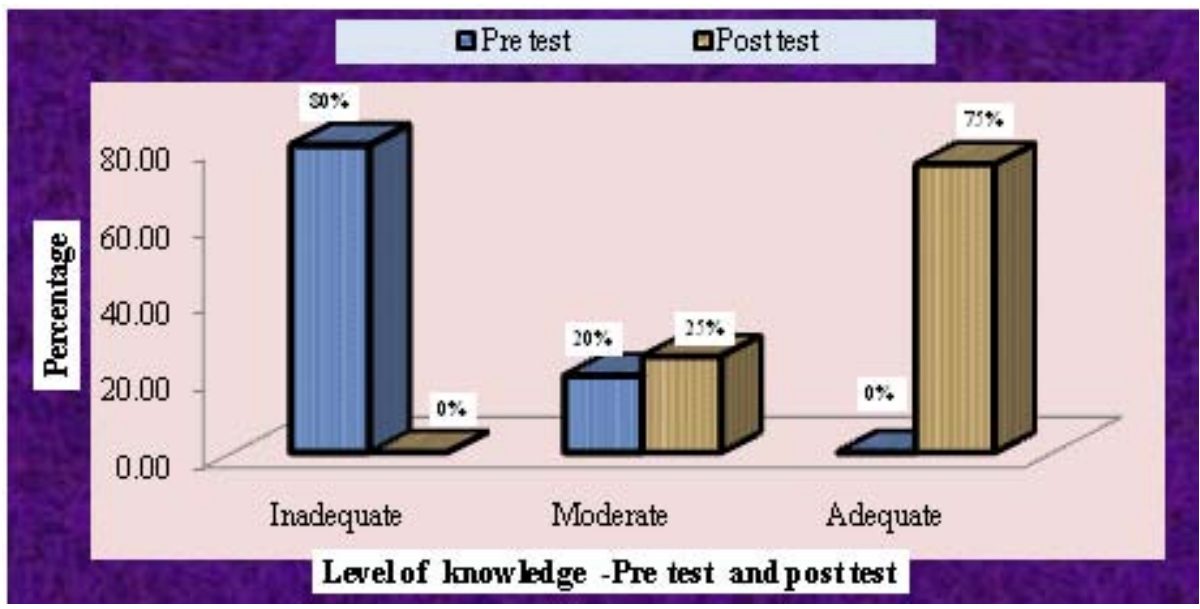

Figure 3: Showed that in pretest 48(80\%) having inadequate, 12(20\%) moderate and no one having adequate knowledge and in posttest $45(75 \%)$ having adequate, $15(25 \%)$ moderate, and no one having inadequate knowledge regarding management of febrile convulsion.

Table 3: Mean, SD and Mean\% of the pre and posttest knowledge on management of febrile convulsion among mothers of under five children, $\mathrm{n}=60$

\begin{tabular}{|c|c|c|c|c|c|c|c|c|c|}
\hline \multirow{2}{*}{ Level of knowledge } & \multicolumn{3}{|c|}{ Pre test } & \multicolumn{3}{c|}{ Post test } & \multicolumn{3}{c|}{ Improved mean } \\
\cline { 2 - 10 } & Mean & SD & Mean\% & Mean & SD & Mean\% & Mean & SD & Mean\% \\
\hline Overall & 11.55 & 3.59 & 38.50 & 24.41 & 3.2 & 81.37 & 12.86 & 2.8 & 42.87 \\
\hline
\end{tabular}

\section{Volume 4 Issue 11, November 2015}




\section{International Journal of Science and Research (IJSR)}

ISSN (Online): 2319-7064

Index Copernicus Value (2013): 6.14 | Impact Factor (2014): 5.611

2.2. Table 4: Distribution of effectiveness of structured teaching programme

\begin{tabular}{|c|c|c|c|c|c|}
\hline $\begin{array}{c}\text { Level of } \\
\text { knowledge }\end{array}$ & \multicolumn{3}{|c|}{ Improved mean } & Paired ' $t$ ' & \multicolumn{1}{c|}{$\begin{array}{c}\text { Level of } \\
\text { significance }\end{array}$} \\
\cline { 2 - 6 } & Mest & $S D$ & Mean\% & Sighly \\
Overall & 12.86 & 2.8 & 42.87 & $37.6^{* *}$ & $\begin{array}{c}\text { Highly } \\
\text { Significance }\end{array}$ \\
\hline
\end{tabular}

**Significant at $\mathrm{p}<0.01$ level, df 59, (t-2.66)

Table 4 shows that overall enhancement mean score is 12.86, SD 2.8, and mean percentage 42.87.Paired t test value is 37.6 significant at 0.01 levels.

Association between posttest knowledge score with their selected demographic variables

Table5. Distribution of association between posttest knowledge score on management of febrile convulsion with their selected demographic variables, $\mathbf{n}=\mathbf{6 0}$

\begin{tabular}{|c|c|c|c|c|c|}
\hline $\begin{array}{c}S . \\
\text { No }\end{array}$ & Area & $d f$ & $\begin{array}{c}\text { 't' } \\
\text { value }\end{array}$ & $\begin{array}{c}\text { Chi } \\
\text { square } \\
\text { value }\end{array}$ & $\begin{array}{c}\text { Chi square } \\
\text { value }\end{array}$ \\
\hline 1 & Type of the family & 1 & 3.84 & 4.75 & $\begin{array}{c}\text { Highly } \\
\text { Significance }\end{array}$ \\
\hline 2 & $\begin{array}{c}\text { Educational Status } \\
3\end{array}$ & 4 & 9.49 & 11.56 & $\begin{array}{c}\text { Highly } \\
\text { Significance }\end{array}$ \\
\hline 4 & $\begin{array}{c}\text { Previous history of } \\
\text { Rupees } \\
\text { Hospitalization }\end{array}$ & 4 & 9.49 & 10.43 & $\begin{array}{c}\text { Highly } \\
\text { Significance }\end{array}$ \\
Significance \\
\hline
\end{tabular}

Note: Significant at $\mathrm{P}<0.05$ level

Table 5 shows there is a significant association between post-test knowledge scores with their selected demographic variables among mothers of under five children. The result of the chi-square presented in table 5 indicate that there was significant association between posttest knowledge score with demographic variables such as type of family, education, income, and previous history of hospitalization, evidenced that there was statistically association at $\mathrm{p}<0.05$ level.

\section{Discussion}

In pretest $48(80 \%)$ were inadequate, $12(20 \%)$ moderate and no one having adequate knowledge regarding management of febrile convulsion. The present result was supported by the findings of a prospective questionnaire-based study was carried out at Children's Hospital Wilder meth, Biel to investigate the effect of febrile seizures on the behavior and emotional situation of parents. Result of the study concluded that knowledge of febrile seizures among parents was insufficient [13]. In the post-test majority of them had $45(75 \%)$ adequate knowledge, 15(25\%) moderate and no one having inadequate knowledge regarding management of febrile convulsion, this result were similar to the study conducted in in Department of Nursing, National Cheng Kung University, Taiwan to evaluate the effects of educational interventions on parental practices for recurrent febrile convulsions. result of this study concluded that compared with the mailed pamphlet, the educational program had significant improvements in recommended practices [14]. The overall mean knowledge score 24.41 obtained by the subject in posttest was higher than the mean knowledge score 11.55 in the pretest and with the improvement score is 12.86. There was significant difference between pre and posttest knowledge score with the $t$ value of 37.6 found to be significant at $\mathrm{p}<0.01$ level. The present result was supported by a pre-experimental one group pre-test and post-test study conducted in selected hospital at Salem to evaluate the effectiveness of Planned Nursing Intervention on prevention of febrile fits in terms of knowledge and practice among mothers of child with fever this study concluded that there was a significant improvement in the knowledge and management of febrile convulsion [15]. The association of demographic variable with post test score of knowledge by using chi square test revealed there statistically significant association with variables such as type of family, education, income, and previous history of hospitalization, evidenced that there was statistically association at $\mathrm{p}<0.05$ level. The study result was supported by a comparative study conducted in the department of Public Health, University School of Medicine, Juntendo to compare the maternal knowledge on fever in children with and without febrile convulsion. The study concluded that mothers of children with a history of febrile seizures demonstrated a higher rate of accuracy in their knowledge of fever than those in the other group. Providing accurate information to family members is essential to provide mothers with both accurate information and emotional support [16].

\section{Conclusion}

This study reveals that there was significant difference in pre and posttest knowledge of mothers of under five children regarding management of febrile convulsion. The study also reveals that there was an association between demographic variable and knowledge level of mothers of under five children regarding management of febrile convulsion.

\section{Implications of the Study}

- Nursing service: The content will help the nursing professionals working in hospital and community to reinforce their knowledge on febrile convulsion.

- Nursing education: Nurse Educator can use the module content to teach the students about febrile convulsion.

- Nursing Research: The findings of the study can be utilized for conducting further study. A large study can be conducted to standardize the STM on febrile convulsion.

- Nursing Administration: The nurse administrator can formulate procedures and policies regarding management of febrile convulsion. They should organize and implement ongoing education and in-service programme regarding management of febrile convulsion to the nurse.

\section{Recommendation}

On the basis of the findings of the study, following recommendations put forward for further research

- A similar study can be replicated on a large sample to generalize the findings

- A study can be conducted by including additional demographic variable.

- The study can be conducted among fathers of under five children.

\section{Volume 4 Issue 11, November 2015}




\section{International Journal of Science and Research (IJSR) \\ ISSN (Online): 2319-7064}

Index Copernicus Value (2013): 6.14 | Impact Factor (2014): 5.611

- A similar study can be replicated among care givers in orphanage.

\section{Limitation of the Study}

- Small number of subject limits generalization

- Only a single domain that knowledge is considered in the present study.

\section{Ethical Consideration}

The researcher had taken permission from the parent institution to conduct research study. Permission was taken from the medical director and medical superintendent of RajaRajeswari Medical College and Hospital to conduct the study. Consent was taken from parturient mothers before data collection.

\section{Acknowledgement}

"God is great "My sincere special gratitude to Mr. Jophin Joseph for preparing this article, I owe my sincere thanks and gratitude to all those who have contributed towards the successful completion of this endeavor.

\section{References}

[1] Carol S, Camfield. February Convulsion [Online]. 2004 Jan 4 [cited 2006 Apr 8]. URL:http://www.medlink.com

[2] National Institute of Neurologic Disorders and Stroke. Febrile convulsion fact sheet [Online]. 2011 Oct 31 [Cited 2011 Nov 10]; [10 screens].Available from: URL:http://www.ninds.nih.gov

[3] Farrell K, Ran D. The management of febrile convulsion. BMCJ .2011 Jul 1; 53.

[4] American Academy of Pediatrics (AAP). Febrile Seizures. Retrieved on 2009 Nov 10http://www.intelihealth.com/IH/int

[5] Vadani V. Pediatric febrile convulsion-An Indian perspective". Indian Journal of Pediatrics 2005 Jan: 35(4):55-9.

[6] Sillanp M, Camfield P, Camfield C, Haataja L, Aromaa $\mathrm{M}$, Helenius $\mathrm{H}$ e.tal. Incidence of febrile seizures in Finland: prospective population-based study". J Pediatr Neurol. 2008 Jun; 38(6):391-4.

[7] Siddiqui. Febrile convulsion in children relationship of family history to type of convulsion and age at presentation".Journal of Ayub Medical College Abbottabad. 2002 Oct-Dec; 14(4):26-8.

[8] Verity CM, Butler NR, Golding J. Febrile convulsions in a national cohort followed up from birth. IPrevalence and recurrence in the first five years of life" Br Med J (Clin Res Ed). 1985 May 4; 290(6478):130710.

[9] Kumar B, Pramesh H, KhatibS. "Febrile convulsion incidence report. Lakeside Institute of Child Health,Bangalore"

.2006cited15Nov2006).http://www.pediatriconcall.com/ fordoctor/Conference abstracts.

[10] SajadiHazaveh M, Shamsi M. - Assssment of mothers' behavior in preventing febrile convulsion in their children in Arak". Journal of Jahrom University of Medical Sciences, Vol. 9, No. 2, Summer 2011.

[11] Al-Nouri L, Basheer K. - Mthers' perceptions of fever in children". J Trop Pediatr. 2006 Apr; 52(2):113-6. www.http//: zaid180@yahoo.com

[12] Bavdekar SB, Ghule R, Jadhav S. Health care-seeking behavior rafter convulsion in children. Indian Journal of Medical Science. 2008 Aug; 62(8):331-5[13]. Tanja flury, Christine aebi, Filippo donati. Febrile seizures and parental anxiety: does information help". Swiss med wkly $2001 ; 131: 556-560$.

[13] Tanja flury, Christine aebi, Filippo donati. Febrile seizures and parental anxiety: does information help". Swiss med wkly $2001 ; 131: 556-560$.

[14]Huang MC, Liu CC, Chi YC, Thomas K, Huang CC. Effects of educational intervention on changing parental practices for recurrent febrile convulsions epilepsia. 2002 Jan; 43(1):81-6 www.http//:meay@mail.ncku.edu.tw

[15] Essays, UK. (November 2013). Discussion of Effectiveness of Planned Nursing Intervention Nursing Essay.

http://www.ukessays.com/essays/nursing/discussion-of research-on-prevention-of-febrile-fits-nursingessay.php.

[16] Sakai R, Niijima S, Marui E . Parental knowledge and perceptions of fever in children and fever management practices: differences between parents of children with and without a history of febrile seizures".Pediatr Emerg Care. 2009 Apr; 25(4):231-37.

\section{Author Profile}

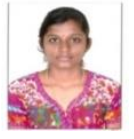

Mrs. Jyothy GeorgereceivedM.Sc. in pediatric nursing from Rajarajeswari College of nursing Bangalore, there after she was working as a staff nurse in Narayana hrudayalaya, Bangalore.

Mr. Jophin Joseph received M.Sc in pediatric nursing from The Karnataka College of nursing, Bangalore. Currently he is working as a lecturer in department of nursing, Jimma University, Ethiopia. 